\title{
Prediction of Internal Combustion Engines Performance related to Fuel Properties using Radial Basis FunCtions
}

\author{
Rogério N. Carvalho ${ }^{1,2}$, Guilherme B. Machado ${ }^{1}$ and Marcelo J. Colaço ${ }^{2}$ \\ ${ }^{1}$ Petrobras Research and Development Center \\ ${ }^{2}$ Department of Mechanical Engineering - Federal University of Rio de Janeiro \\ E-mails: rogerio.carvalho@petrobras.com.br, machadogb@petrobras.com.br, colaco@ufrj.br
}

\begin{abstract}
Accurate simulation of fuel properties influence in internal combustion engines performance is a very complex approach and combines many physical and chemical concepts such as combustion phenomena, chemical kinetics, fluid dynamics, turbulence and thermodynamics. The right modelling of that is still a challenge and currently available software packages for engines simulation usually consider standard or surrogate fuels. Besides that, new engine technologies, including those for sport motor application, can achieve better performances if custom fuels are formulated and applied. This development usually requires a large number of tests with different fuels, which leads to very expensive researches. Therefore, simulation is an option to reduce the number of tests and the associated costs. This paper presents the use of a response surface approach based on Radial Basis Functions to simulate a flexible fuel engine running with distinct blends of iso-octane, n-heptane, toluene and ethanol. Performance, energetic efficiency and pollutant emissions are predicted in different operating conditions.
\end{abstract}

\section{INTRODUCTION}

The development of high quality fuels for internal combustion engines has been increased very largely and became an important research item in the last decades for the main oil and fuel companies in the world. In the beginning of fuel production, only few specification items were defined to simply assure that fuels were able to run engines and vehicles. With the growth of environmental concerns, mainly from the seventies, new properties have being added to fuels specs. Additionally, the development of new engine technologies requires a correspondent fuel quality improvement, not only to achieve better performances, but also to comply with regulatory indexes.

Researches for new fuel development usually require a large number of different tests to cover the main quality attributes such as engine performance, fuel consumption, pollutant emissions, engine cleaning, and parts durability. Therefore, there is a need of expensive laboratory setups, high quantities of different fuel formulations, vehicles, engines, specialized staff and so on, that results in huge budgets and times.

Computational simulation is a very attractive alternative to aid on development costs reduction, not yet as the only tool, but as a first screening of candidate fuel formulations or 
additivations, pointing the experimental effort to the best predicted results. Currently, a number of very powerful engine simulators are available on the specialized market and are largely used by the automotive industry to design and optimize new engines and vehicles. However, as these packages are dedicated to engines development, they normally consider standard or surrogate fuels to run performance simulations for different engine configurations. Nevertheless, fuel development need the opposite configuration, fixing engine parameters and changing fuel properties and compositions.

Phenomenological approaches to simulate fuel performance changes related to their properties deal with very complex disciplines as combustion, turbulence, chemical kinetics, fluid dynamics and thermodynamics, for instance. Usually, these calculations need a large number of coupled equations with very hard mathematical solution and computational effort, and in fact are still not completely dominated. But, the statistical treatment of available experimental data or the knownledge of a defined experimental setup behavior can be used to build powerful and feasible computational alternatives to accurately predict new fuel formulations performance.

In this work, a response surface approach, based on a Radial Basis Functions (RBF) model was applied on a previously available experimental data set, composed by fuel properties and engine operating conditions, with their corresponding performance, efficiency and emission results. This data set was acquired from a flexfuel engine running with different blends of iso-octane, n-heptane, toluene and ethanol. This study is still under development and this paper presents preliminary results obtained in an extensive job, devoted to build new computational tools to be applied on the Petrobras Research and Development Center in future research projects for new fuels or additives formulations.

\section{RADIAL BASIS FUNCTIONS}

Radial Basis Functions (RBFs) is becoming an established approach in recent years to simulate different problems in many areas of engineering [1-10]. This technique was first proposed by Kansa [11], after the work of Hardy [12] on multivariate approximation.

Kansa proposed the asymmetric collocation method that starts by building an approximation to the field of interest, which are normally displacement components, from the superposition of RBFs, globally or compactly supported, conveniently placed at points in the domain and/or at the boundary.

RBFs may be classified into two main groups, as defined in Colaço et al [13]:

a) The globally supported ones namely the multiquadrics (MQ, $\sqrt{\left(x-x_{j}\right)^{2}+c_{j}^{2}}$ where $c_{j}$ is a shape parameter), the inverse multiquadrics, thin plate splines, Gaussians etc;

b) The compactly supported ones such as the Wendland [14] family (for example, $(1-r)_{+}^{n}+p(r)$ where $p(r)$ is a polynomial and $(1-r)_{+}^{n}$ is 0 for $r$ greater than the support).

It is worth mentioning that there are several other methods for automatically constructing multi-dimensional response surfaces available in the open literature [15-18]. 
The RBF model used in this work has the following general form, for a function of $L$ variables $x_{i}, i=1, \ldots, L[13]$ :

$$
f(\mathbf{x}) \approx s(\mathbf{x})=\sum_{j=1}^{N} \alpha_{j} \phi\left(\left|\mathbf{x}-\mathbf{x}_{j}\right|\right)
$$

where $\mathbf{x}=\left\{x_{1}, \ldots, x_{i}, \ldots, x_{L}\right\}, f(x)$ is the exact value of the function and $s(x)$ is the estimated value obtained by interpolation. [19].

This approximation is solved for the $\alpha_{j}$ unknowns from the system of $N$ linear equations, and the Multiquadrics Radial Basis Functions (Eq. 2) were used in this work, where the shape parameter $c_{j}$ is used to control the smoothness of the RBF:

$$
\phi\left(\left|\mathbf{x}-\mathbf{x}_{j}\right|\right)=\sqrt{\left(x_{i}-x_{j}\right)^{2}+c_{j}^{2}}
$$

\subsection{Performance Measurements}

In order to verify the accuracy of the metamodels developed in this work, three different metrics were used: R Square $\left(R^{2}\right)$, relative average absolute error (RAAE), and relative maximum absolute error (RMAE) [20].

\section{- R Square}

$$
R^{2}=1-\frac{\sum_{i=1}^{n}\left(y_{i}-\hat{y}_{i}\right)^{2}}{\sum_{i=1}^{n}\left(y_{i}-\bar{y}\right)^{2}}=1-\frac{\text { MSE }}{\text { variance }}
$$

where $y_{i}$ is the observed value, $\hat{y}_{i}$ is the corresponding predicted value and $\bar{y}$ is the mean of the observed values. It is the ratio between the mean square error (MSE), which represents the distance of the metamodel from the real simulation model, and the variance that captures how irregular the problem is. Larger $R^{2}$ values mean more accurate metamodels.

- Relative Average Absolute Error

$$
R A A E=\frac{\sum_{i=1}^{n}\left|y_{i}-\hat{y}_{i}\right|}{n * \operatorname{STD}}
$$

where STD is the standard deviation. Smaller RAAE values indicate more accurate metamodels.

\section{- Relative Maximum Absolute Error}

$$
R M A E=\frac{\max \left(\left|y_{1}-\hat{y}_{1}\right|,\left|y_{2}-\hat{y}_{2}\right|, \ldots,\left|y_{n}-\hat{y}_{n}\right|\right)}{\operatorname{STD}}
$$

Since RMAE indicates the maximum error in one region of the design space, small RMAE values are preferred. Even when $R^{2}$ and RAAE present very good overall accuracy, RMAE can be large if there is a large error in one region. Since it cannot 
show the overall performance, it is not as important as $R^{2}$ and RAAE.

Also, percentage deviations between experimental and predicted values of each testing point were calculated.

\section{EXPERIMENTAL DATA}

Response surfaces based on RBF models were built based on fuel properties and experimental performance data that were available in the previous work of Machado et al. [21-23], In that study, it was presented a comprehensive analysis of surrogate fuels performance related to their composition. Ternary plots of response surfaces were statistically determined based on normalized concentrations of three basic gasoline components (iso-octane, n-heptane and toluene) and mathematical models were developed relating the percent volumetric concentration of each component with various different fuel properties and engine performance parameters $[24,25]$.

In that study, a DoE was built to cover the central region of a fuel blend composition ternary diagram, as shown in Figure 1. The central region is the best range to represent the properties of a commercial gasoline in Brazil. In fact, the mixtures are not specified commercial gasolines, but represent well the range of variation of their properties and the engine operated smoothly with all of them. Ten blends of iso-octane, n-heptane and toluene were defined. A fixed concentration of $25 \%$ by volume of anhydrous ethanol was added to all surrogate blends to comply with the Brazilian commercial gasoline regulation (A_E25 to J_E25).

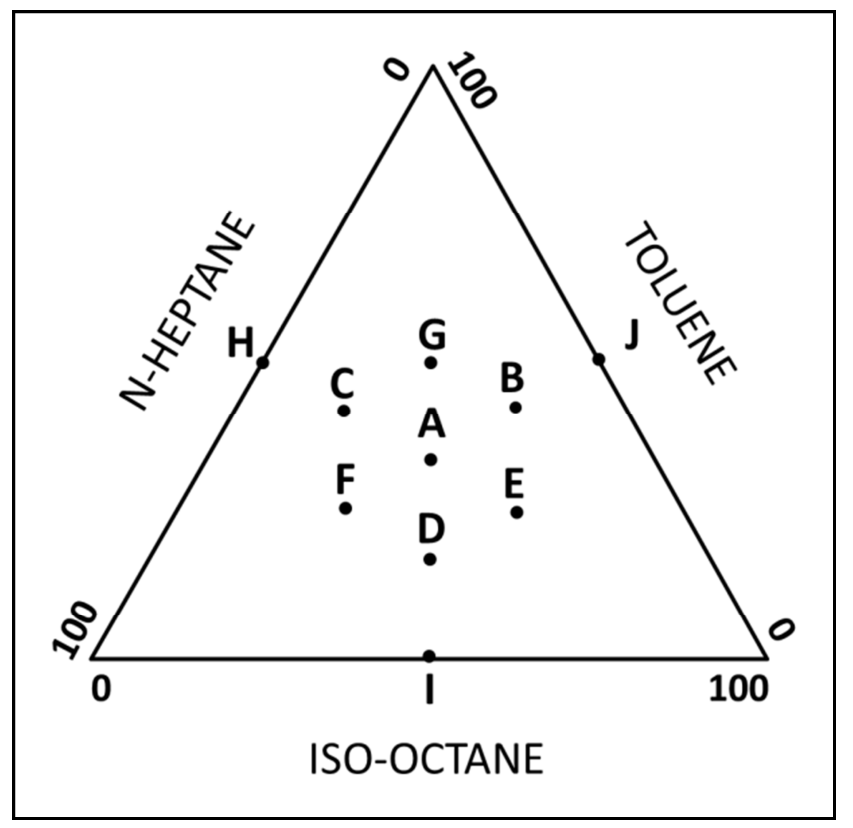

Figure 1: Ternary diagram of fuel blends composition [21].

Additionally, experimental data from four alternative variations of anhydrous ethanol content in mixture B (B_E00 to B_E75); pure anhydrous ethanol (EAC); and pure hydrous ethanol (EHC) were available. Table 1 summarizes all the 16 mixture compositions. 
Table 1: Matrix of experimental fuels composition.

\begin{tabular}{ccccc}
\hline \multirow{2}{*}{ Mixture } & \multicolumn{4}{c}{ Volumetric Concentration (\%) } \\
\cline { 2 - 5 } & Iso-octane & N-heptane & Toluene & EAC \\
\hline A_E25 & 25 & 25 & 25 & 25 \\
\hline B_E25 & 31.25 & 12.5 & 31.25 & 25 \\
\hline C_E25 & 12.5 & 31.25 & 31.25 & 25 \\
\hline D_E25 & 31.25 & 31.25 & 12.5 & 25 \\
\hline E_E25 & 37.5 & 18.75 & 18.75 & 25 \\
\hline F_E25 & 18.75 & 37.5 & 18.75 & 25 \\
\hline G_E25 & 18.75 & 18.75 & 37.5 & 25 \\
\hline H_E25 & 0 & 37.5 & 37.5 & 25 \\
\hline I_E25 & 37.5 & 37.5 & 0 & 25 \\
\hline J_E25 & 37.5 & 0 & 37.5 & 25 \\
\hline B_E00 & 41.67 & 16.66 & 41.67 & 0 \\
\hline B_E15 & 35.42 & 14.16 & 35.42 & 15 \\
\hline B_E50 & 20.84 & 8.32 & 20.84 & 50 \\
\hline B_E75 & 10.42 & 4.16 & 10.42 & 75 \\
\hline EAC & NA & NA & NA & 100 \\
\hline EHC & NA & NA & NA & 94.7 \\
\hline NA nd
\end{tabular}

NA - not applicable.

Machado et al. [21-23] performed their experiments on a four-cylinder four-stroke Fiat Fire 1.4L Tetrafuel engine that is able to run with pure gasoline, Brazilian regular gasoline (that is a gasohol with $18 \%$ to $25 \%$ of anhydrous ethanol by volume), any mixtures of Brazilian gasoline and hydrous ethanol, pure hydrous ethanol and also natural gas. Details of the main engine specifications are presented in Table 2.

Table 2: Specifications of Fiat Fire 1.4L Tetrafuel engine.

\begin{tabular}{lc}
\hline Total swept volume & $1368 \mathrm{~cm} 3$ \\
\hline Number of cylinders & 4 in line \\
\hline Cylinder diameter & $72 \mathrm{~mm}$ \\
\hline Stroke & $84 \mathrm{~mm}$ \\
\hline Piston bore & $71.9 \mathrm{~mm}$ \\
\hline Compression ratio & $10.35: 1$ \\
\hline Valves per cylinder & 2 \\
\hline Camshaft & $1($ Overhead $)$ \\
\hline
\end{tabular}

A MoTeC m800 programmable electronic control unit (ECU) replaced the original one and tests followed the ISO 1585 standard [26] at six different operating points, varying speed and throttle position, in order to cover a wide range of engine operating conditions. Two fixed values of Lambda, the ratio between the real and stoichiometric air/fuel ratio, were defined: 0.9 for full-load, with wide open throttle (WOT) and 1.0 for partial load.

In order to achieve the maximum break torque (MBT), spark timing was varied according to fuel and engine operating conditions, limited to knocking occurrence and a maximum exhaust gas temperature of $900{ }^{\circ} \mathrm{C}$. At least three measurements of torque and fuel consumption were performed for each fuel after a minimum of one minute of engine stabilization per operating condition. $\mathrm{CO}$ and $\mathrm{CO}_{2}$ emissions were acquired with a Napro Modal 2010 non-dispersive infrared analyzer. The maximum experimental expanded uncertainty was $0.6 \%[21,23]$. 
A picture of the engine test bench can be seen in Figure 2.

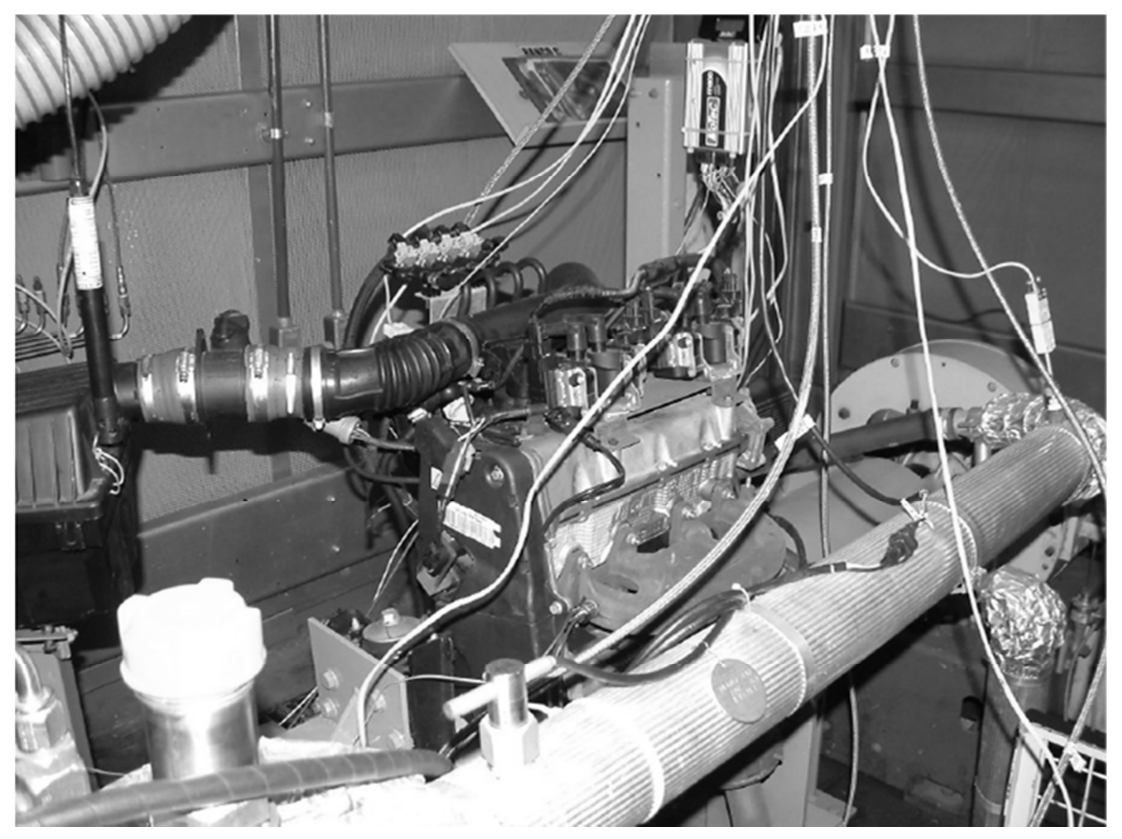

Figure 2: Test bench with Fiat Fire 1.4L Tetrafuel engine.

\section{RBF MODEL CONSTRUCTION}

To construct this first simplified version of the model, based on RBFs, the following list of available experimental data was used, including fuel properties, operating conditions and measured test results with the 16 fuels listed in Table 1:

a) Fuel Properties: density; lower heating value; enthalpy of vaporization; $\mathrm{H} / \mathrm{C}$ and $\mathrm{O} / \mathrm{C}$ molar ratios; stoichiometric air/fuel ratio; and anti-knock index;

b) Operating Conditions: engine speed and spark timing (crank angle degrees BTDC);

c) Experimental Measurements: torque; specific fuel consumption (SFC); volumetric efficiency; $\mathrm{CO}$ and $\mathrm{CO}_{2}$ emissions.

Input data set was built by normalizing all available fuel properties and operating conditions listed above and the linear system was solved for each experimental measured parameter. Twelve of the available fuels in Table 1 were used to build response surfaces (Eqs. 1 and 2) and four of them were chosen to test and validate the model after construction. As can be noticed in the experimental fuel composition ternary diagram (Fig. 1), mixtures B, C and D are in the middle of domain. Thus, mixtures B_E25, C_E25 and D_E25 were selected to validate the surfaces. Also, the mixture B with $15 \%$ of EAC (B_E15) was chosen. In this simulation, only three full load operating conditions, with 5500, 3875 and $2250 \mathrm{rpm}$ were used.

The shape parameter $c_{j}$ was fixed as the lowest distance between two points in the domain. Computational code was made in Fortran language. The linear system was composed by a 36 x 36 matrix and solved by the LSARG subroutine from IMSL package [27]. 


\section{RESULTS AND DISCUSSION}

Figure 3 presents comparisons between predicted and experimental results for the four selected fuel mixtures. Torque, specific fuel consumption, volumetric efficiency, $\mathrm{CO}$ and $\mathrm{CO}_{2}$ emissions are analyzed. Simulations of torque, specific fuel consumption and volumetric efficiency have achieved good adherences for most of the cases. Emissions predictions had worse performances. However, this level of simulation can already be considered satisfactory from the point of view of tendencies analysis.

As it can be seen, prediction models were able to indicate that mixtures C_E25 and D_E25 produce lower output torque and higher fuel consumption and could be eliminated in a preliminary selection, reducing experimental efforts. On the other hand, if emissions were the main concern, predictions indicated clearly the best performance of mixture D_E25.
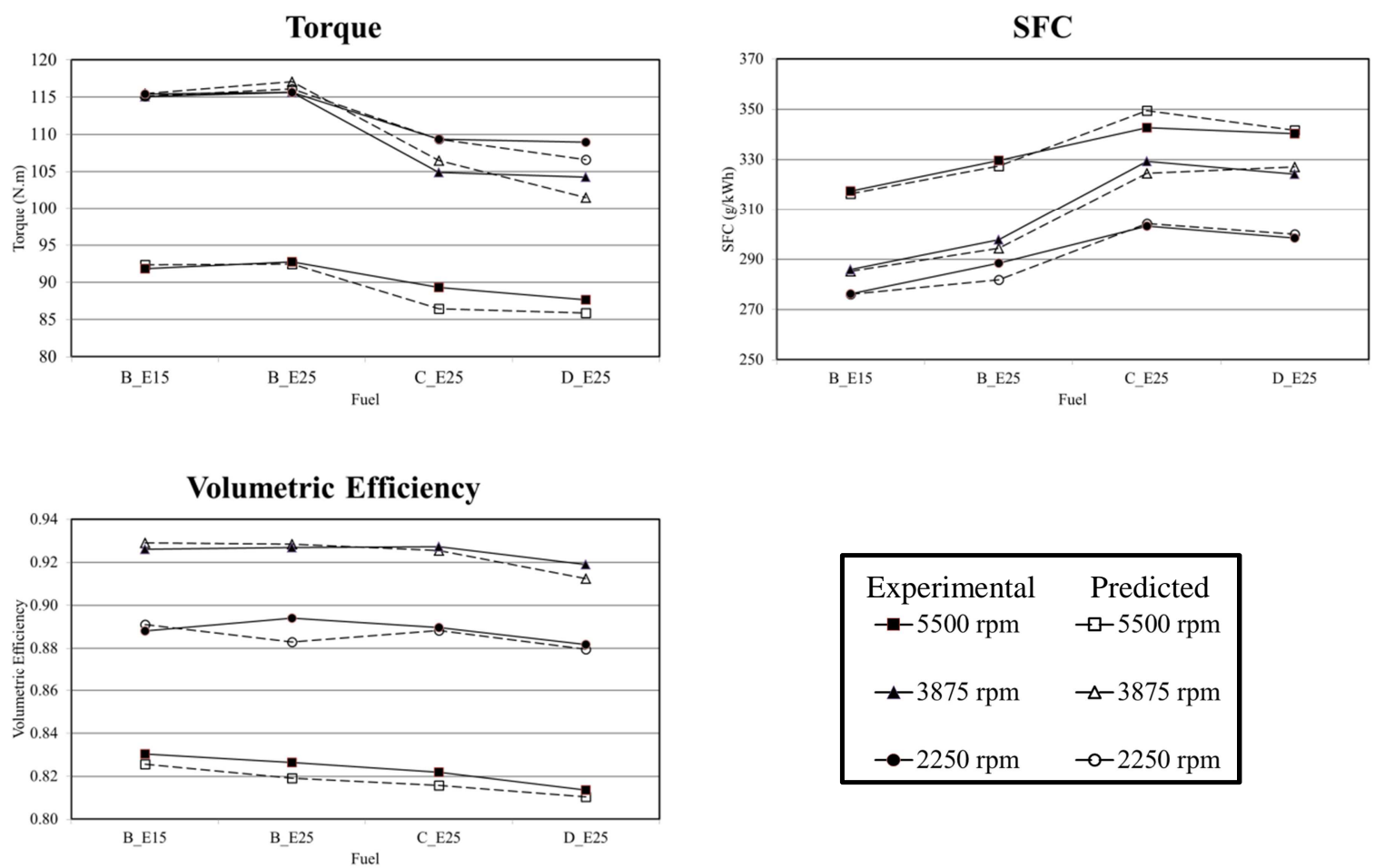

\section{CO}

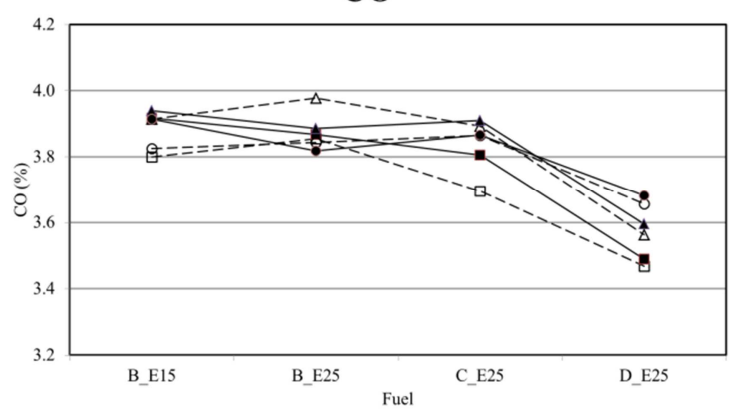

$\mathrm{CO}_{2}$

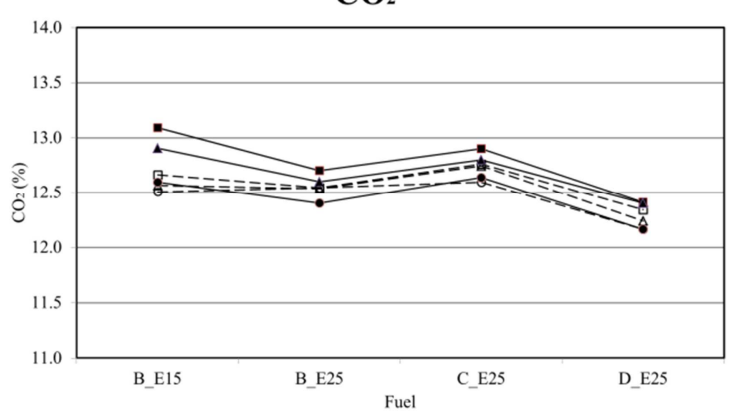

Figure 3: Comparisons between predicted and experimental results. 
In order to verify the accuracy of the predicted results, Figure 4 presents their correlations with the experimental ones. It can be noticed that, as already verified in Figure 3 analysis, for torque, specific fuel consumption and volumetric efficiency, strong correlations were achieved, but were not so good for emissions simulations. However, most of the result deviations from the perfect prediction line (predicted $=$ experimental) were lower than $\pm 3 \%$.
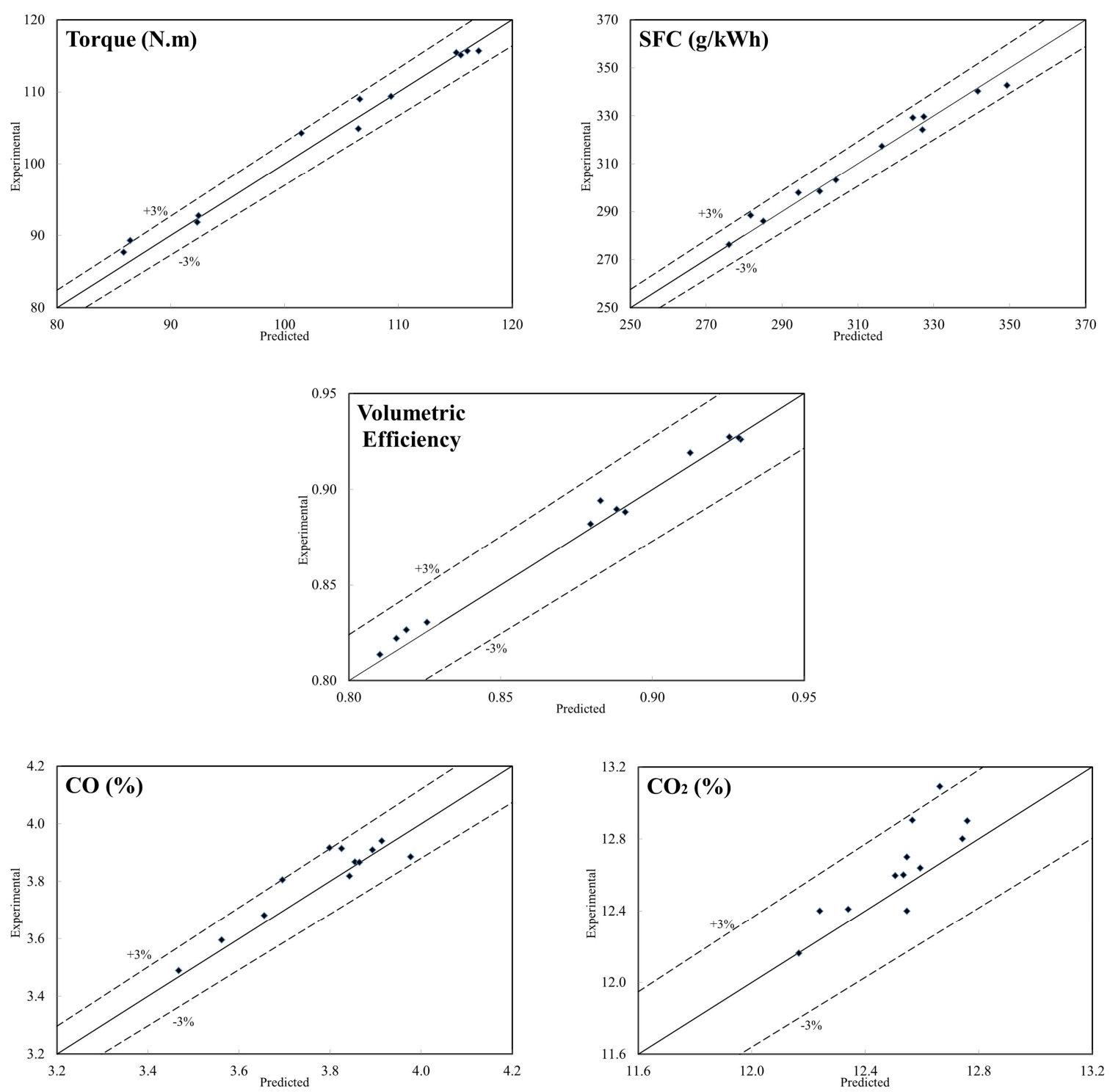

Figure 4: Comparisons between predicted and experimental results.

Table 3 presents the summary of performance indexes. As graphically observed in Figure 4, torque, SFC and volumetric efficiency obtained high $R^{2}$ levels and low values of RAAE and RMAE, indicating a good adjust for response surfaces. As also already noticed, low $R^{2}$ and high RAAE and RMAE values, from $\mathrm{CO}$ and $\mathrm{CO}_{2}$ emissions response surfaces, indicate poor agreement between prediction and experimental values. 
Table 3: Performance Indexes.

\begin{tabular}{c|ccccc}
\hline $\begin{array}{c}\text { Performance } \\
\text { Index }\end{array}$ & Torque & BSFC & $\begin{array}{c}\text { Volumetric } \\
\text { Efficiency }\end{array}$ & CO & CO2 \\
\hline $\mathbf{R}^{\mathbf{2}}$ & 0.9776 & 0.9744 & 0.9850 & 0.7987 & 0.4681 \\
\hline RAAE & 0.1165 & 0.1253 & 0.1028 & 0.3425 & 0.5570 \\
\hline RMAE & 0.2703 & 0.3104 & 0.2638 & 0.8522 & 1.6904 \\
\hline
\end{tabular}

Figure 5 summarizes all absolute deviations between predicted and experimental values. Besides the low performance indexes that were obtained for emission simulations, it can be noticed that only two predictions deviations were higher than $3 \%$, among all of them, which indicates that, at least for tendencies indications as discussed above, this first model is satisfactory enough.

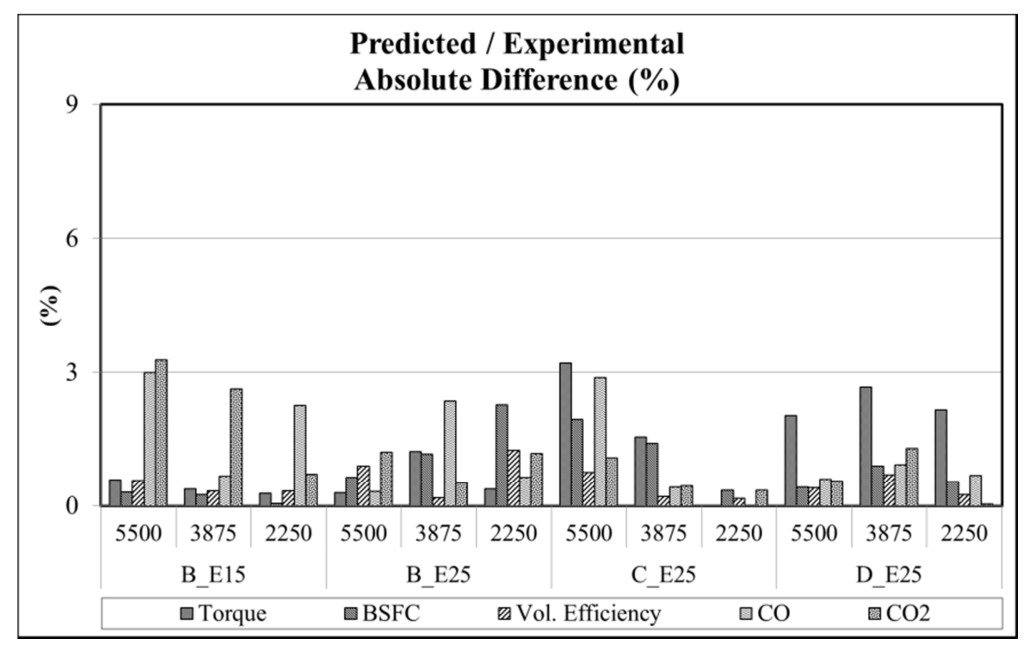

Figure 5: Absolute deviations between predicted and experimental values.

\section{CONCLUSIONS}

This paper presented the first step of a response surface prediction model development, based on Radial Basis Functions (RBF) to predict performance and emissions of an internal combustion engines. Models were built with a simplified approach for the method and first results presented satisfactory performances.

The obtained results have satisfactory accuracy for torque, specific fuel consumption and volumetric efficiency and poor correlations for $\mathrm{CO}$ and $\mathrm{CO}_{2}$ emissions.Models could capture very well engine performance tendencies related to fuel properties, which is already satisfactory to choose candidate formulations for experimental developments.

Next steps of this model development include: an adaptive choice of the shape parameter $c_{j}$ to optimize the surfaces to each output parameter; the introduction of polynomials to improve the response surface domain; comparison with other methods, such as Kriging technique [13]; and uncertainty analysis. 


\section{ACKNOWLEDGEMENTS}

Authors acknowledge the support provided by Petrobras Research and Development Center (CENPES) in the conduction of this research. Prof. Colaço also acknowlegdes the financial support provided by CNPq, FAPERJ, CAPES and PRH37/ANP (Brazilian agencies for fostering Science and Technology).

\section{REFERENCES}

[1] Queipo, N. V., Haftka, R, T., Shyy, W., Goel, T., Vaidyanathan, R., Tucker, P. K., Surrogate-based analysis and optimization, Progress in Aerospace Sciences 41 (2005), pp. $1-28$.

[2] Xie, D., Sun, X., Bai, B., Yang, S., Multipobjective optimization based on response surface model and its application to engineering shape design, IEEE Transactions on Magnetics, Vol. 44, n. 6, June 2008.

[3] Colaço, M. J., Teixeira, C. V., Dutra, L. M., Thermodynamic simulation and optimization of diesel engines operating with diesel and biodiesel blends using experimental data, Inverse Problems in Science and Engineering, 18:6, 787-812 (2010).

[4] Pandian, M., Sivapirakasam, S. P., Investigation on the effect of injection system parameters on performance and emission characteristics of a twin cylinder compression ignition direct injection engine fuelled with pongamia biodiesel-diesel blend using response surface methodology, Appled Energy 88 (2011), pp. 2663-2676.

[5] Kurimoto, N., Suzuki, M., Yoshino, M., Nishijima, Y., Response surface modeling of diesel spray parameterized by geometries inside of nozzle, SAE 2011-01-0390, 2011.

[6] Abuhabaya, A., Fieldhouse, J., Brown, D., The optimization of biodiesel production by using response surface methodology and its effect on compression ignition engine, Fuel Processing Technology 113 (2013), pp. 57-62.

[7] Fang, S., Ren, W., Perera, R., A stochastic model updating method for parameter variability quantification based on response surface models and Monte Carlo simulation, Mechanical Systems and Signal Processing 33 (2012), pp. 83-96.

[8] Jakobsson, S., Saif-Ul-Hasnain, M., Rundqvist, R., Edelvik, F., Andersson, B., Patriksson, M., Ljungqvist, M., Lortet, D., Wallesten, J., Combustion engine optimization: a multiobjective approach, Optim Eng DOI 10.1007/s11081-009-9090-6, (2009).

[9] Deshmukh, S. C., Senthilnath, J., Dixit, R. M., Malik, S. N., Pandey, R. A., Vaidya, A. N., Omkar, S. N., Mudliar, S. N., Comparison of radial basis function neural network and response surface methodology for predicting performance of biofilter treating toluene, Journal of Software Engineering and Applications, 2012, 5, pp. 595-603.

[10] Kumar, S., Srinivasa Pai, P., Shrinivasa Rao, B. R., Radial-basis-function network-based prediction of performance and emission characteristics in a bio diesel engine run on WCO ester, Advances in Artificial Intelligence, vol. 2012, article ID 610487.

[11] Kansa, E.J., Multiquadrics - a scattered data approximation scheme with applications to computational fluid dynamics - II: solutions to parabolic, hyperbolic and elliptic partial differential equations, Comput. Math. Appl. 19 (1990), pp. 149-161.

[12] Hardy, R.L., Multiquadric equations of topography and other irregular surfaces, J. Geophys. Res. 176 (1971), pp. 1905-1915.

[13] Colaço, M. J., Dulikravich, G.S., Sahoo, D., A response surface method-based hybrid optimizer, Inverse Problems in Science and Engineering, 16:6, (2008) 717 - 741.

[14] Wendland, H., Error estimates for interpolation by compactly supported radial basis functions of minimal degree, J. Approx. Theory 93 (1998), pp. 258-272.

[15] Lancaster, P., and Salkauskas, K., Curve and Surface Fitting: An Introduction, 
Academic Press, Harcourt Brace Jovanovic, London, San Diego, New York, 1986.

[16] Kaufman, M, Balabanov, V., Burgee, S. L., Giunta, A. A., Grossman, B., Mason, W. H., Watson, L. T., Haftka, R. T., Variable complexity response surface approximations for wing structural weight in HSCT design, in AIAA Paper 96-0089, Proceedings of the 34th Aerospace Sciences Meeting and Exhibit, Reno, NV, 1996.

[17] Madala, H.R., and Ivakhnenko, A.G., Inductive learning algorithms for complex systems modeling, CRC Press, Boca Raton, Florida, 1994.

[18] IOSO NM Version 1.0, User's Guide, IOSO Technology Center, Moscow, Russia, 2003.

[19] Buhmann, M.D., Radial basis functions on grids and beyond, International Workshop on Meshfree Methods, Lisbon, 2003.

[20] Jin, R., Chen, W., and Simpson, T.W., Comparative studies of metamodeling techniques under multiple modeling criteria, in Proceedings of the 8th AIAA/USAF/NASA/ISSMO Multidisciplinary Analysis \& Optimization Symposium, AIAA 2000-4801, Long Beach, CA, 6-8 September 2000.

[21] Machado, G. B., Barros, J. E. M., Braga, S. L., Silva, A. H. M. F. T., Oliveira, E. J, Azevedo, E. C. Z., Braga, C. V. M, Methodologies for fuel development using surrogate fuels on spark ignition engines, 21st SAE BRASIL International Congress and Exhibition, São Paulo, Brasil (2012) - SAE 2012-36-0477.

[22] Machado, G. B. Barros, J. E.M,. Braga, S. L, Braga, C. V. M., Oliveira, E. J. Silva, A.H.M.F.T., Carvalho, L.O., Investigations on surrogate fuels for high-octane oxygenated gasolines, Fuel 90 (2011), pp. 640-646.

[23] Machado G.B., Metodologias para desenvolvimento de combustíveis e determinação da velocidade de propagação de chama em motores de ignição por centelha, D.Sc. Thesis, PUC-Rio, Rio de Janeiro, 2012.

[24] Montgomery D.C., Runger G.C., Applied statistics and probability for engineers, John Wiley \& Sons, New York, 1994.

[25] Calado V.M.A., Montgomery D.C. (2003) Design of Experiments using Statistica, Epapers, Rio de Janeiro, Brazil..

[26] ISO 1585, Road Vehicles - Engine Test Code - Net Power, International Organization for Standardization, Switzerland, 1992.

[27] IMSL Fortran Numerical Library, User's Guide Math Library, Version 7.0. 